\title{
Design and synthesis of hydroxyferroquine derivatives with antimalarial and antiviral activities.
}

Christophe Biot, Wassim Daher, Natascha Chavain, Thierry Fandeur, Jamal Khalife, Daniel Dive, Erik De Clercq

\section{Supporting Information}

Elemental Analyses for hydroxyferroquine derivatives 2, 3 and 4.

2-[(2-\{[(7-chloro-4-quinolyl)amino]methyl\}ferrocenylmethyl)amino]-1-ethanol (2) Anal Calcd for $\mathrm{C}_{23} \mathrm{H}_{24} \mathrm{ON}_{3} \mathrm{FeCl}$ : C, 61.42; H, 5.38; N, 9.34. Found: C, 61,53; H, 5.17; N, 9.56.

2-[(2-\{[(7-chloro-4-quinolyl)amino]methyl\}ferrocenylmethyl)(methyl)amino]-1-ethanol (3)

Anal Calcd for $\mathrm{C}_{24} \mathrm{H}_{26} \mathrm{ON}_{3} \mathrm{FeCl}$ : C, 62.15; H, 5.65; N, 9.06. Found: $\mathrm{C}, 62,26 ; \mathrm{H}, 5.57 ; \mathrm{N}$, 9.16 .

2-[(2-\{[(7-chloro-4-quinolyl)amino]methyl\}ferrocenylmethyl)(ethyl)amino]-1-ethanol (4) Anal Calcd for $\mathrm{C}_{25} \mathrm{H}_{28} \mathrm{~N}_{3} \mathrm{FeCl}$ : C, 62.84; H, 5.91; N, 8.79. Found: C, 62,79; H, 5.86; N, 8.85. 


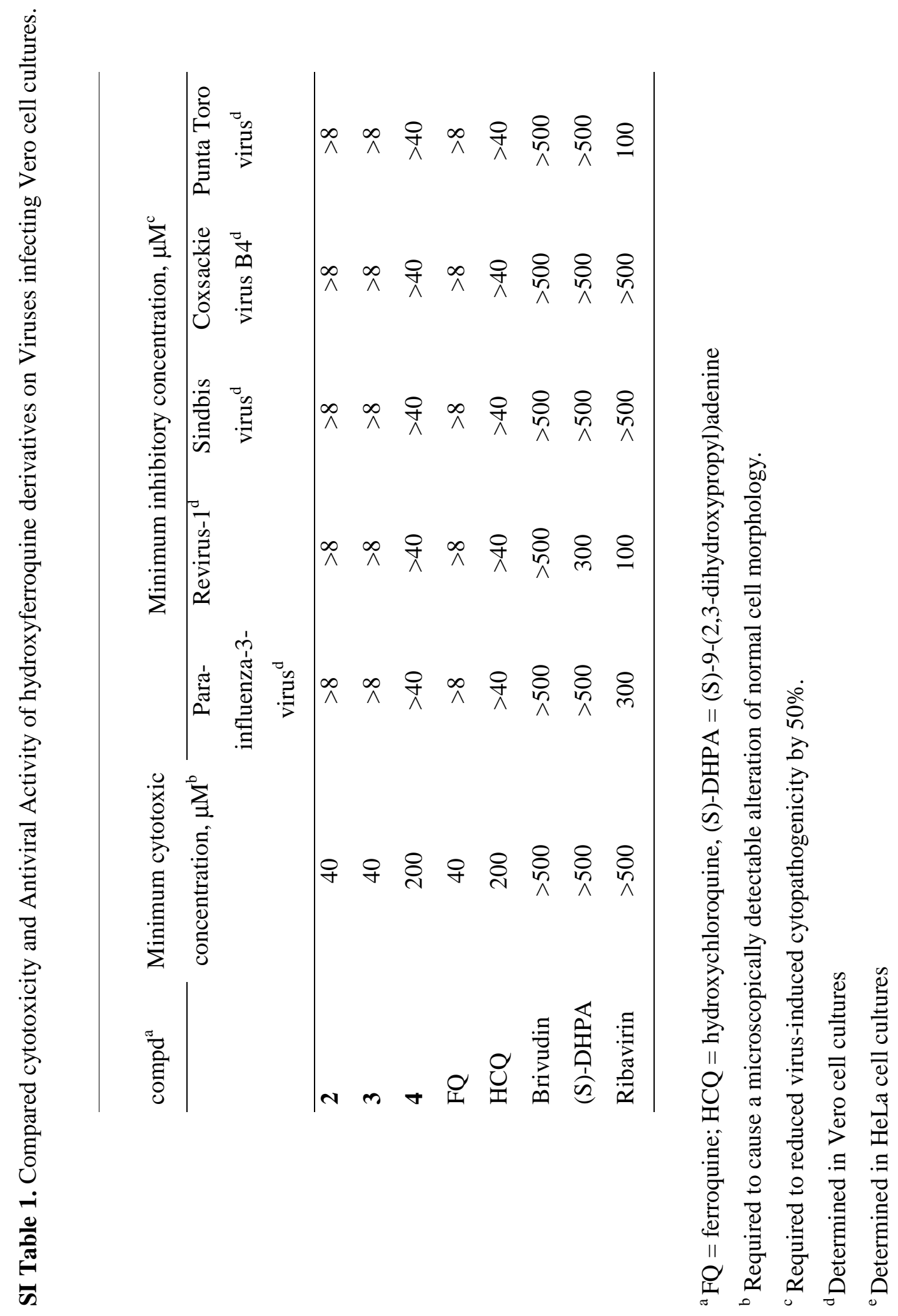




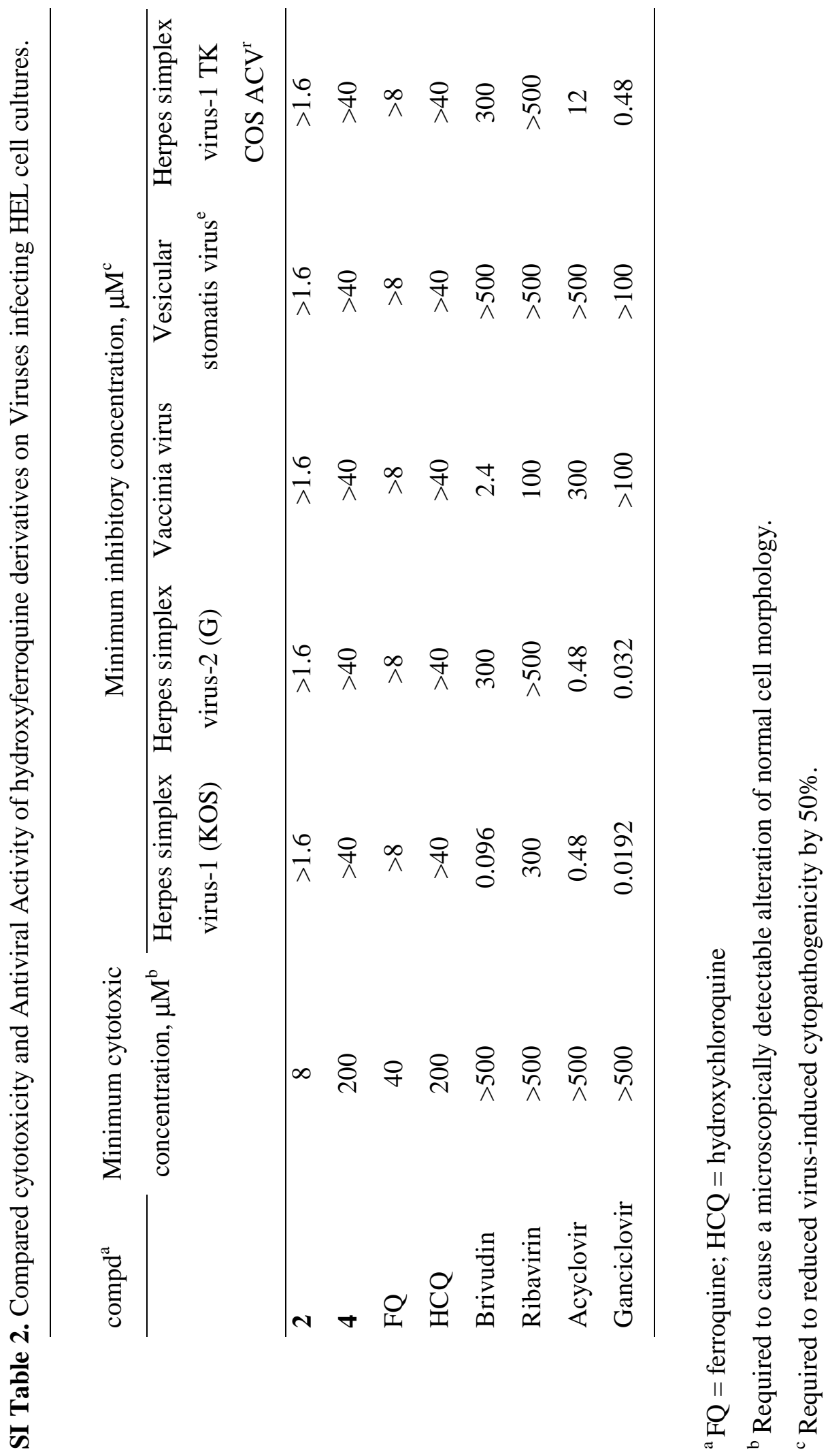




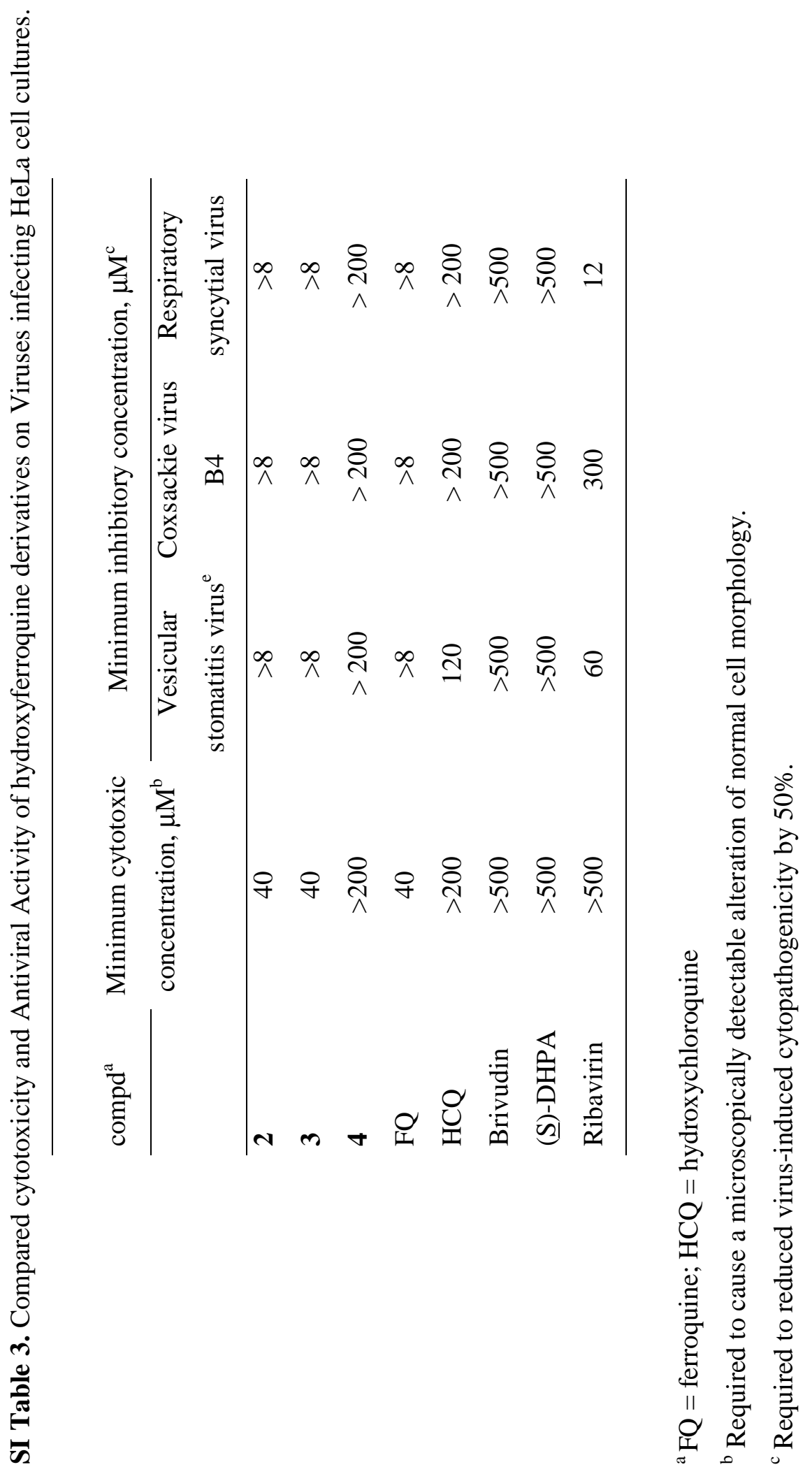




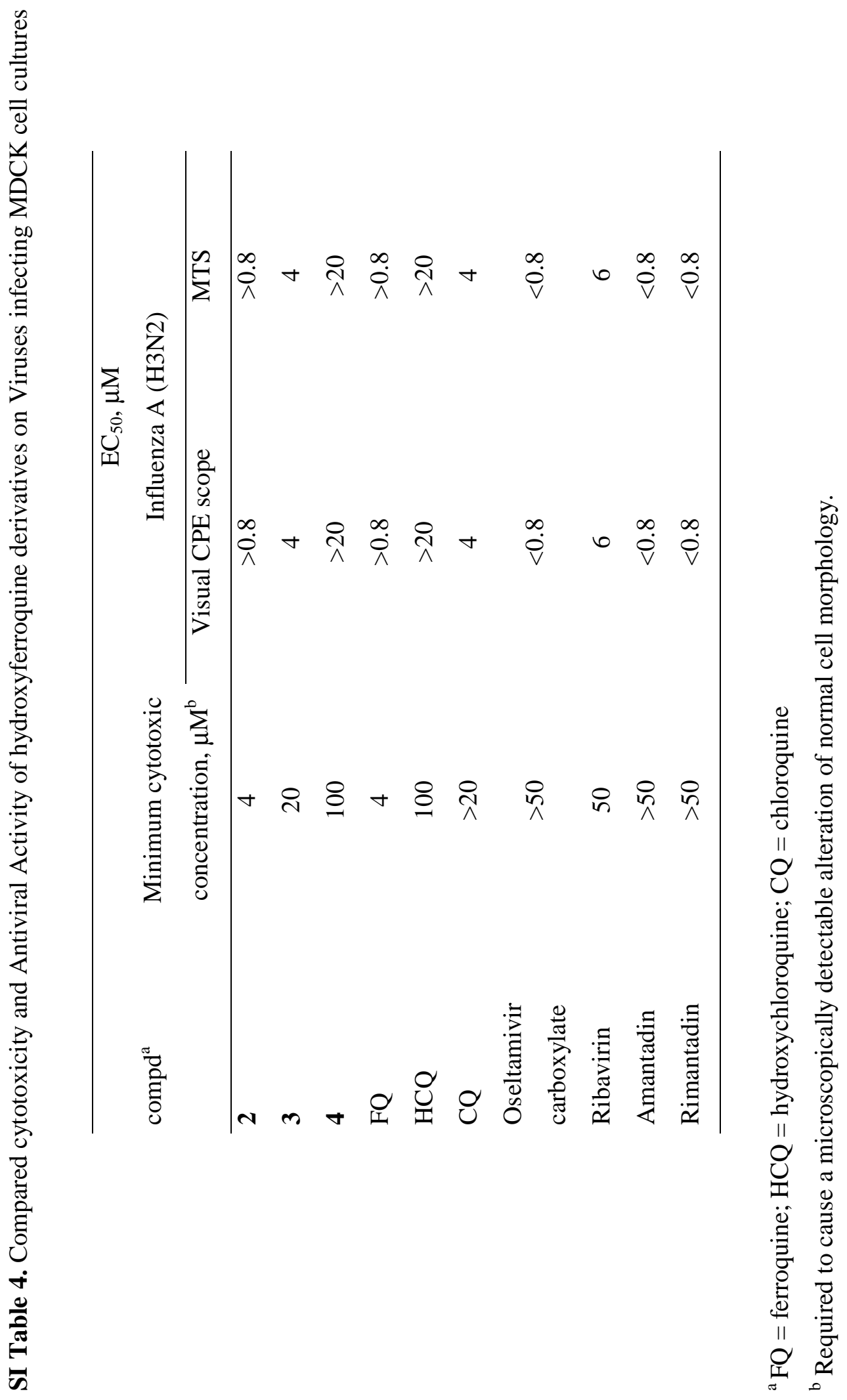

